\title{
Análise da relação entre subsidiária brasileira e matriz de corporação norte-americana com foco na gestão de RH
}

\section{Analysis of the relationship between Brazilian subsidiary and U.S. corporate headquarter focused in HR management}

\author{
Claudia Cristina Bitencourt \\ Unisinos - Brasil \\ claudiacb@unisinos.br \\ Debora Boll \\ Unisinos - Brasil \\ debora_boll@yahoo.com.br
}

\begin{abstract}
Recebido em 24 de outubro de 2011. Alterado em 8 de agosto de 2013. Aprovado em 22 de dezembro de 2013
\end{abstract}
Editor Responsável: Edson Roberto Scharf, Dr.

Processo de avaliação por double blind review

\section{Resumo}

As organizações multinacionais são chamadas de agentes da globalização, por sua relevância econômica e social. Dada sua complexidade, por terem de atuar ao mesmo tempo global e localmente, surge a necessidade de se estudar sua dinâmica de gestão de pessoas como ponto chave para a compreensão das práticas contemporâneas de gestão. Nesse cenário, este estudo busca compreender como se desenvolve a gestão de RH nessas organizações, quando a área tem o papel estratégico da atração, desenvolvimento e retenção de pessoas. Desenvolveu-se, a partir de um apanhado teórico, um estudo de caso em uma corporação norte-americana com foco na relação entre sua subsidiária brasileira e a matriz corporativa. Pôde-se verificar que a gestão de RH em subsidiárias de multinacionais é altamente complexa por sofrer fortes influências do sistema de negócios do país de origem da multinacional e da cultura e legislação do país de operações. A área trabalha, então, no sentido de equilibrar simultaneamente as demandas vindas da matriz corporativa e as locais. Identificou-se, além disso, na corporação estudada, apesar da forte centralização e padronização em corporações norteamericanas, um esforço para que a função $\mathrm{RH}$ evolua através do estímulo à interação entre unidades para troca das práticas bem sucedidas.

\section{Palavras-Chave}

Gestão estratégica, internacionalização, recursos humanos

\begin{abstract}
Multinational organizations are called agents of globalization, due their economic and social relevance. Given their complexity, by having to act globally and locally at the same time, there is a need to study their RH operation dynamic as a key point to understanding the contemporary management practices. In this scenario, this study aims to understand how the HR management is
\end{abstract}


developed in those companies, when the RH area has the strategic role of attraction, development and retention of people. Supported by a theoretical overview, we present a case study developed in a North American corporation focusing on the relationship between its Brazilian subsidiary and the corporate headquarter. The main results points out that the HR management in subsidiaries of multinationals is highly complex suffering strong influences from the business system of country of origin of the multinational and the culture and laws of the country of operations. The area works, then in order to balance the demands coming from both corporation and local subsidiary. It was also identified despite the strong centralization and standardization in North American corporations, an effort to ensure that the HR function develop based on the interaction between units to exchange successful practices.

\section{Keywords}

Strategic management, internationalization, human resources

\section{Introdução}

Acesso

desenvolvimento de tecnologias e mudanças sociais têm contribuído para a emergência de mercados e competidores, crescentes pressões de acionistas e altas exigências do mercado. Para muitas empresas, competir globalmente é questão de sobrevivência, o que demanda atuação em distintos ambientes gerindo unidades em vários países (ULRICH, 2000; MILAN, 2011, OGBONNAYA et al, 2012). Esse cenário faz com que os gestores sejam desafiados a gerenciar globalmente, como se o mundo fosse um grande mercado, ao mesmo tempo em que tem de gerenciar localmente, como se fosse um grande número de mercados separados e fragilmente ligados (BOZKURT E ALEXANDER 2011; ANDO E PAIK, 2013; BARTLETT E GHOSHAL, 1992; MAZMANIA et al, 2013). Para vencer esses desafios, a área de Recursos Humanos (RH) tem um papel fundamental: precisa estrategicamente atrair, desenvolver e reter pessoas (ULRICH, 2000, ANCA-IOANA, 2013). O papel estratégico do RH já é bastante referenciado quando a área depara-se com a missão de acompanhar e interferir na formulação das estratégias de negócios da empresa, passando a gestão de pessoas a constituir-se em diferencial competitivo (CANÇADO et al, 2005, ANCA-IOANA, 2013).

No cenário brasileiro, pesquisas recentes demonstram que a área de recursos humanos de algumas empresas já atua de forma mais estratégica ou está em processo de transição. Dentre as organizações com gestão estratégica de recursos humanos, a grande maioria é internacionalizada, ou seja, são multinacionais brasileiras ou subsidiárias de multinacionais estrangeiras (LACOMBE e TONELLI, 2001; ALBUQUERQUE e BOSQUETTI, 2005; HANASHIRO, TEIXEIRA e ZEBINATO, 2001, SILVA e FLEURY, 2013, MIRANDA e MENDEZ, 2012).

Nesse mesmo sentido, a importância das empresas multinacionais para a economia mundial, denominadas de "agentes da globalização", só vem aumentando. Nos países emergentes, devido ao crescimento acelerado, os novos postos de trabalho em multinacionais de origem americana representam um aumento de 47,5\% (SLAUGHTER e D'ANDREA, 2012). Reforça-se, assim, a importância de se estudar as práticas de gestão das multinacionais como ponto chave para a compreensão das práticas contemporâneas de gestão.

Estudos recentes sobre empresas multinacionais tratam da questão de convergência em contraponto à continuidade da diversidade, nas formas organizacionais e práticas em diferentes ambientes (FERNER et al, 2013). No que tange à relação entre subsidiárias de multinacionais e outras subsidiárias ou matrizes, busca-se analisar as causas e formas de centralização, descentralização e/ou integração nessa relação, o que inclui transferência de conhecimento, melhores práticas e instrumentos de controle (EDWARDS et al, 2013).

Especificamente falando das multinacionais norte-americanas, elas são conhecidas por padronizarem, 
centralizarem e formalizarem mais fortemente suas políticas e práticas de gestão dentre suas subsidiárias, se comparadas a multinacionais de outros países, como, por exemplo, as européias, as quais procuram respeitar mais a cultura local de suas subsidiárias estrangeiras (ALMOND et al, 2005, PARRY et al, 2008, ALMOND, 2011).

Dada a complexidade da gestão de organizações multinacionais e os consequientes desafios para as áreas de $\mathrm{RH}$ dessas organizações, surge, assim, a necessidade de se analisar seu modelo de gestão a fim compreender como elas gerem a relação entre matriz e subsidiárias e a transferência de práticas de gestão entre unidades. E, a partir da compreensão de sua estrutura geral de gestão, pode-se estudar como a gestão de recursos humanos é desenvolvida nas corporações multinacionais.

Nessa perspectiva, a partir da compreensão do modelo de gestão, o presente estudo busca analisar a gestão de recursos humanos em organizações multinacionais, atentando para a relação matriz-filial e suas diferenças em termos de cultura, estrutura e práticas gerenciais. Estuda-se na pesquisa o caso uma corporação norte-americana com foco na relação entre sua subsidiária brasileira e a matriz corporativa. Para tanto, através de um estudo de caso, a pesquisa busca inicialmente analisar como ocorreu $\mathrm{o}$ processo de incorporação da subsidiária a corporação; caracterizar o modelo de gestão internacional da corporação; avaliar o papel estratégico da subsidiária brasileira para a corporação e verificar como ocorre a transferência de práticas na corporação; para, então, identificar os desafios e influenciadores da gestão internacional estratégica de pessoas. Destaca-se que os dados foram coletados no período de de abril a maio de 2008, quando um novo sistema de recursos humanos foi implementado, representando a padronização das práticas utilizadas pela matriz americana.
Justifica-se esse estudo pelo fato da tendência crescente observada em processos de uniões internacionais e outras estratégias, que envolvem o relacionamento entre empresas situadas em diferentes países e a complexidade gerada nessas relações. Destaca-se, além disso, a importância estratégica conferida à função recursos humanos e a relevância econômica e social das organizações multinacionais. $\mathrm{O}$ estudo é pertinente, também, pela carência de pesquisas internacionais sobre subsidiárias latinas de multinacionais, uma vez que quase que a totalidade dos estudos sobre esse tema analisa as subsidiárias asiáticas, européias, africanas e/ou australianas, com foco em países desenvolvidos (EDWARDS e KURUVILLA, 2005; AGUZZOLI, 2006).

No Brasil, da mesma forma, a maioria dos estudos em gestão internacional de pessoas dedica-se a análise da questão da expatriação (AGUZZOLI, 2006, BOZKRUT e ALEXANDER, 2011).

O presente artigo está estruturado em seis partes. $\mathrm{Na}$ parte inicial, introdutória, constam a contextualização, tema, objetivos, e justificativa do estudo. $\mathrm{Na}$ segunda e terceira parte são desenvolvidos os aspectos teóricos que referenciam a pesquisa. Depois disso, apresenta-se a metodologia da pesquisa. Na sessão cinco apresentam-se e discutemse os resultados da pesquisa. Na parte final, então, são realizadas as considerações finais da pesquisa.

\section{Organizações Multinacionais e suas Subsidiárias}

As organizações multinacionais são as grandes players da economia mundial e, por gerirem diferentes unidades tendo de ser globais e locais ao mesmo tempo, é de suma importância compreender o modo como elas operam (SCHULER, DOWLING e DE CIERI, 1993, FOURIE, 2013). Sundaram e Black (1992) as conceituam como organizações que realizam transações em/entre duas entidades soberanas, operando sob um 
sistema de tomada de decisões que permite influência em recursos e competências, onde as transações estão sujeitas à influência de fatores externos ao país de origem da organização.

A expansão internacional de uma empresa para se transformar em uma multinacional pode acontecer através de várias estratégias: investimento Greenfield (abertura de filiais); aquisição de empresas já existentes; joint ventures; alianças estratégicas (ROCHA e ALMEIDA, 2006, CARNEIRO et al, 2011). Nos países emergentes, como o Brasil, principalmente depois do processo de liberalização econômica, somente tem crescido o processo de fusões e aquisições entre empresas estrangeiras e domésticas, através do qual, organizações estrangeiras buscam ou aumentar sua participação de mercado ou defender-se do crescimento de suas rivais (VASCONCELOS, CALDAS e WOOD JR., 2004, RAMSEY et al, 2012).

Em relação às consequiências dos processos de fusões e aquisições, Caldas e Tonelli (2011) identificaram em sua pesquisa que no cenário brasileiro eles são permeados, de um lado, por um clima grupal agressivo, por perdas identitárias e de memória e por sentimentos de frustração que provocam o desgaste emocional; por outro lado, as imagens infantis de que tudo será resolvido no futuro impedem a visão clara da realidade dos conflitos desse processo. Já Rondinelli e Black (2000) e RAMSEY et al (2012) argumentam que possíveis conflitos entre os interesses das empresas dos diferentes países podem ser resolvidos se os atores econômicos desenvolverem uma relação de cooperação, uma vez que as corporações multinacionais são parceiras do processo de longo prazo de transformação econômica.

Vasconcelos, Caldas e Wood Jr. (2004) destacam que o sucesso de um processo de aquisição/fusão não está diretamente ligado ao país de origem das empresas, mas sim ao processo em si, no qual se deve: evitar métricas agressivas de desempenho, melhorar estratégias de comunicação ao máximo, buscar reduzir as demissões em massa e desenvolver uma atitude de dignidade e respeito com os funcionários da empresa adquirida principalmente.

A partir dos 1980 foi forte o foco das pesquisas em administração sobre a gestão das corporações multinacionais organizações complexas que precisam atingir uma variedade de níveis de globalidade e localidade para se manterem competitivas. A complexidade das multinacionais deriva, também, da utilização de combinações formais e informais de controle, de forma a operarem interconectadas em distintos entornos geográficos (QUINTANILLA, 2002; SCHULER, DOWLING e DE CIERI, 1993).

Dentre os estudos pioneiros sobre a gestão das unidades internacionais de multinacionais, destaca-se a pesquisa inicial de Bartlett e Ghoshal (1986), os quais verificaram que dois modelos pouco integradores e colaborativos podiam ser identificados: o modelo das nações unidas - as subsidiárias recebiam recursos, procedimentos e critérios de avaliação padronizados não sendo consideradas sua importância estratégica ou ambiente no qual estavam instaladas - e a síndrome da hierarquia da matriz - os gestores das matrizes tomavam as decisões chave e viam os gestores das subsidiárias como meros implementadores. Esses modelos possuíam claramente limitações acarretando grandes perdas em várias empresas.

Mais recentemente, os mesmos autores Bartlett e Ghoshal (1992, 1998) propuseram o conceito de empresa transnacional que visa superar o modelo simplista de exploração dos fatores tradicionais da competitividade da multinacional, tais como; matéria-prima e mão-de-obra barata e potencial de mercado. A corporação multinacional que adota a estratégia transnacional se organiza na forma de uma rede diferenciada, em que 
cada uma das subsidiárias possui diferente relevância estratégica. Cada subsidiária contribui de maneira diferenciada, mas de forma integrada. A empresa transnacional busca integrar as vantagens das economias de escala combinadas com a capacidade de responder a demandas específicas dos diversos mercados em que a empresa atua.
Em relação aos papéis das subsidiárias de corporações multinacionais, várias tipologias foram desenvolvidas por diversos autores nos últimos tempos - uma síntese das principais pode ser visualizada no quadro $1, \quad$ a seguir.

\begin{tabular}{|l|c|c|c|}
\hline \multicolumn{1}{|c|}{ PAPÉIS DESEMPENHADOS PELAS SUBSIDIÁRIAS EM CORPORAÇÕES MULTINACIONAIS } \\
\hline & $\begin{array}{c}\text { Implementador Local } \\
\text { (escopo de produtos, } \\
\text { funções e geográfico } \\
\text { limitado) }\end{array}$ & $\begin{array}{c}\text { Contribuidor } \\
\text { Especializado } \\
\text { (especialistas em certas } \\
\text { funções ou atividades, } \\
\text { mas muito controlada e } \\
\text { coordenada) }\end{array}$ & $\begin{array}{c}\text { Mandato Mundial } \\
\text { (desenvolve e implementa } \\
\text { as estratégias corporativas } \\
\text { junto com a matriz) }\end{array}$ \\
\hline $\begin{array}{l}\text { D'Cruz (1986) } \\
\text { Bartlett e Ghoshal } \\
\text { (1992) }\end{array}$ & Filial da Matriz & $\begin{array}{c}\text { Globalmente } \\
\text { Racionalizada }\end{array}$ & $\begin{array}{c}\text { Mandato de Produtos } \\
\text { Mundiais }\end{array}$ \\
\hline $\begin{array}{l}\text { Jarillo e Martinez } \\
\text { (1990) }\end{array}$ & Autônoma & Contribuidora & Líder Estratégica \\
\hline $\begin{array}{l}\text { Roth e Morrison } \\
\text { (1992) }\end{array}$ & Receptiva & Ativa \\
\hline
\end{tabular}

Quadro 1: Diferentes papéis desempenhados por subsidiárias

Fonte: Adaptado de Borini et al (2001)

As subsidiárias implementadoras locais têm seu escopo geográfico limitado a um único país, assim como um escopo muito limitado de produtos e funções. A função da subsidiária é reproduzir e vender, quem sabe com algumas adaptações, os produtos vindos de outras empresas da corporação, mas preferencialmente da matriz (BARTLETT e GHOSHAL, 1986; BARTLETT e GHOSHAL, 1992; BIRKINSHAW e MORRISON, 1995; BORINI et al, 2001; D'CRUZ, 1986; JARILLO e MARTINEZ, 1990; ROTH e MORRISON, 1992).

As subsidiárias contribuidoras especializadas são consideradas especialistas em certas funções ou atividades, mas suas atividades são altamente coordenadas e controladas com as atividades de outras subsidiárias. São caracterizadas por um baixo nível de valor agregado nas atividades locais e elevada interdependência com outras subsidiárias e a matriz (BARTLETT e GHOSHAL,
1986; BARTLETT e GHOSHAL, 1992; BIRKINSHAW e MORRISON, 1995; BORINI et al, 2001; D'CRUZ, 1986; JARILLO e MARTINEZ, 1990; ROTH e MORRISON, 1992).

O papel mais ativo e com maior grau de autonomia a ser desempenhado pelas subsidiárias é a de subsidiária com mandato mundial, de grande importância estratégica que, conjuntamente com a matriz, desenvolve e implementa as estratégias corporativas. Esta subsidiária pode ter responsabilidade global ou regional para uma linha de produtos, área de negócios ou todos os negócios de determinada área geográfica. Ela cria competências para a corporação, seja por reunir capacidades e recursos estratégicos aliados a um mercado estrategicamente importante; seja por ser escolhida pela matriz para ser responsável por alguma atividade de âmbito global; ou por ter desenvolvido reconhecimento e responsabilidade internacional decorrente 
de sua orientação empreendedora ou iniciativa. Os fatores característicos de uma subsidiária com mandato mundial são: a criação de valor para a corporação multinacional; a sua competitividade global; e o reconhecimento pelas outras unidades da corporação a respeito de suas competências (BARTLETT e GHOSHAL, 1986; BARTLETT e GHOSHAL, 1992; BIRKINSHAW e MORRISON, 1995; BORINI et al, 2001; D'CRUZ, 1986; JARILLO e MARTINEZ, 1990; ROTH e MORRISON, 1992).

Com o passar do tempo, o desenvolvimento do país, o estímulo da matriz e outros fatores, as subsidiárias podem alterar seu papel ou relevância estratégica para a corporação. Essa mudança é importante tanto para as corporações como para o país de atividade. Para a corporação, as condições favoráveis de contexto competitivo representam oportunidades para o desenvolvimento de novos produtos, tecnologias e competências em locais diferenciados. Para os países de atividade, a presença de subsidiárias com mandato mundial, representa a evolução das firmas locais e uma inserção mais qualificada na economia global (BORINI et al, 2001, RAMSEY et al, 2012).

Outro importante aspecto em gestão de multinacionais e sua relação com subsidiárias é a transferência de práticas. Do ponto de vista teórico, coexistem dois modelos que explicam a transferência de práticas em uma corporação multinacional: o institucionalista, de Kostova (1998), que enfatiza as motivações e os incentivos, como responsáveis pelo sucesso ou fracasso de transferências internacionais de rotinas; e, outro de tom evolucionista, de Szulanski (1996), que preconiza investimentos em sistemas organizacionais, para aumentar as possibilidades de sucesso da transferência de práticas organizacionais. Saka (2002) diferencia a transferência e a internacionalização de práticas: a internacionalização refere-se à adoção por parte dos funcionários do significado e atitude que existe na prática, ao invés de meramente compreender sua forma; a transferência é a adoção de práticas sem que se internalize sua essência.

A transferência é uma replicação da prática entre as unidades da corporação na busca de ampliação da sua vantagem competitiva. Se o conhecimento fosse todo codificável, a transferência seria apenas de informações. Mas, como o conhecimento também é tácito e as práticas estão ancoradas em outros aspectos (o ambiente da organização e o contexto cultural), a transferência de práticas organizacionais é uma tarefa complexa (FERNANDES e PROCHNIK, 2001, GAMMELGAARD e RITTER, 2008).

Em se tratando da relação entre a matriz e subsidiária, Birkinshaw e Hood (1998) demonstram que um forte relacionamento de trabalho tem um grande impacto nos processos de construção de competências das subsidiárias. As iniciativas das subsidiárias são avaliadas muito mais pela qualidade da relação (tanto em termos de confiança, credibilidade e conhecimento) que pelos méritos técnicos. Na relação matriz e subsidiária, quanto mais fortes e de maior qualidade esses fatores (confiança, credibilidade e conhecimento), menores as chances de desinvestimento na subsidiária. Portanto, quanto mais forte a relação de trabalho e o grau de integração normativo entre matriz e subsidiárias, menor a chance da subsidiária trabalhar de modo não alinhado às estratégias corporativas (BIRKINSHAW E MORRINSON, 1995; GHOSHAL e NOHRIA, 1997, ANDERSSON et al, 2001).

Observa-se, portanto, que mecanismos de controle e autonomia dados à subsidiária dependem de alguns fatores essenciais: a gestão e a estratégia de internacionalização da matriz, as características do país de origem da matriz (cultura corporativa, modelos de gestão), a complexidade do contexto da subsidiária (natureza da indústria, forças competitivas 
e dinâmicas do setor); e disponibilidade de recursos (matriz e filial) (TAGGART, 1997; QUINTANILLA, 2002).

Todos esses aspectos da gestão em organizações multinacionais, bem como da relação entre matrizes e subsidiárias, impactam e são impactados pelo modelo de gestão de pessoas adotado. Por isso, na sessão seguinte são apresentados os conceitos relacionados à gestão estratégica de RH em organizações multinacionais.

\section{Gestão Internacional Estratégica de Recursos Humanos}

A literatura contemporânea sobre gestão de recursos humanos põe em questão a tradicional contribuição/função do departamento de recursos humanos, ao mesmo tempo em que é sugerido um novo modelo para a área, destacando-se a gestão estratégica de pessoas como pano de fundo para alinhar as pessoas à estratégia da organização e promover mudanças organizacionais gerando respostas mais efetivas e adequadas aos desafios do ambiente empresarial. Profundas alterações já ocorreram, quando temas como gestão de competências e processo de aprendizagem organizacional estão sendo assimilados e estimulados pelas organizações como uma forma para criar condições para o desenvolvimento das pessoas e conseqüentemente das empresas. Ao profissional de $\mathrm{RH}$ cabe, pois, preocupar-se mais intensamente com a identificação, captação e retenção de talentos bem como a criação de um ambiente aberto à mudança e aprendizagem (ALBUQUERQUE e BOSQUETTI, 2005; ALBUQUERQUE e FISCHER, 2001, MCDONNELL et al, 2010; FARNDALE et al, 2010; DOUTHITT e MONDORE, 2013).

Alguns pontos centrais de uma abordagem estratégica de RH são: reconhecer o impacto do ambiente externo; reconhecer o impacto da competição e a dinâmica do mercado de trabalho; possuir um foco no longo prazo (três a cinco anos); focar os resultados da escolha e tomada de decisão; considerar toda a força de trabalho envolvida com a organização; e, ser integrada com a estratégia de toda a corporação (ANTHONY, PERREYE e KACMAR, 1996, DOUTHITT e MONDORE, 2013). Em outras palavras, destaca-se o alinhamento entre as estratégias organizacionais e $\mathrm{o}$ desenvolvimento das pessoas.

Propondo um modelo de reestruturação da gestão de pessoas, dadas as novas circunstâncias organizacionais, Ulrich (1998, DOUTHITT e MONDORE, 2013, RAMONA e ANCA, 2013) apresenta os novos múltiplos papéis que o RH deve exercer: gestor das estratégias de recursos humanos; gestor da transformação e mudança; gestor da infra-estrutura da empresa; e gestor da contribuição dos funcionários. A estrutura de múltiplos papéis é uma alternativa para definir objetivos abrangentes, conhecer as expectativas dos clientes e estabelecer metas de valor agregado para os profissionais de $\mathrm{RH}$.

Neste contexto, Albuquerque (1999) destaca as premissas básicas da gestão estratégica de pessoas: a valorização dos talentos humanos; atração e manutenção de pessoas de alto potencial e qualificação para o trabalho; criação de condições favoráveis à motivação individual e à mobilização dos grupos em torno das metas organizacionais; possibilidade de desenvolvimento profissional; oferecimento de incentivos vinculados a resultados obtidos pela equipe e resposta às mudanças do ambiente organizacional.

Considerando essa diversidade de papéis e as premissas envolvidas na reestruturação da gestão de pessoas e, extrapolando-as ao contexto de organizações multinacionais, as quais enfrentam o desafio de ser localmente sensíveis e globalmente competitivas ao mesmo tempo, a gestão estratégica de recursos humanos torna-se ainda mais indispensável. 
$\mathrm{Na}$ academia, a gestão internacional de pessoas é analisada sob três perspectivas: a gerência cultural, que examina o comportamento organizacional dos trabalhadores a partir de um olhar internacional; a comparação das relações industriais que busca analisar as políticas de gestão de pessoas em diferentes países; e a abordagem contemporânea que estuda aspectos de gestão de pessoas em organizações multinacionais, a qual é enfatizada nesta pesquisa (DOWLING e WELCH, 2005).

Schuler, Dowling e De Cieri (1993, p. 703) propõem uma tipologia integradora de gestão estratégica internacional de recursos humanos e a conceituam da seguinte forma: "assuntos, funções e políticas e práticas de gestão de recursos humanos que resultam das atividades estratégicas de organizações multinacionais e que impactam nos objetivos e decisões dessas organizações".

No caso de subsidiárias estrangeiras de multinacionais, Quintanilla (2002) destaca que a gestão internacional de pessoas necessita equilibrar as "grandes quatro forças" que a influenciam: o sistema de nacional de negócios do país de origem da corporação; a cultura do país de atividade; os recursos e capacidades gerenciais da subsidiária; e as características do setor em que a empresa atua. A influência da sede organizacional é a força mais evidente e a responsável por determinar o comportamento e o papel das subsidiárias. O país de operações exerce, através de sua cultura e de instituições idiossincráticas, pressões locais que levam as subsidiárias a se adaptarem às rotinas do país. A indústria local, por sua vez, influencia a subsidiária porque sua natureza e característica têm repercussões diretas no desenvolvimento de políticas e práticas de Gestão de Pessoas. Já, a capacidade e recursos diretivos das subsidiárias determinam seu desenvolvimento e contribuem com o incremento da matriz.
Kopp (1994) corrobora com essa idéia afirmando que a cultura nacional de um país é mais influente do que a cultura organizacional da matriz. Isto justifica o fato de que a adoção de algumas práticas é efetiva na sede da empresa, mas ineficiente em outros países de operação. Ou seja, é significativa a ascendência cultural de um país sobre as práticas internacionais de gestão de pessoas adotadas pela multinacional. Sugere-se que as mesmas práticas implementadas na sede organizacional poderiam ser levadas a diversos países, com distintas culturas, embora os resultados nunca sejam idênticos.

Em relação às influências do país de origem da empresa multinacional sobre a gestão de pessoas de suas subsidiárias, pesquisas demonstram seguidamente que multinacionais norte-americanas são as mais propensas a ter sistemas de gestão de recursos humanos formalizados e centralizados (FERNER et al, 2004, LAWLER et al, 2013). Corporações multinacionais norte-americanas sempre tenderam a exportar formas organizacionais e métodos de gestão estabelecidos nos Estados Unidos para o mundo todo. As práticas de remuneração baseada em desempenho, políticas de fomento à diversidade - demandadas pela legislação anti-racismo norte-americana e o movimento dos direitos civis - e a posição contrária à regulação pelo estado das relações empregatícias são levadas para as subsidiárias do mundo inteiro (ALMOND et al, 2005; ALMOND, 2011). Essas empresas preferem, também, modos de controle das subsidiárias burocráticos a sociais, o que se reflete da predominância de políticas formais e globais (FERNER e QUINTANILLA, 1998).

Junto a isso, surge como evidência o fato de que as multinacionais norteamericanas também apresentam barreiras à difusão reversa, ou seja, a difusão para a matriz de práticas desenvolvidas em subsidiárias estrangeiras, especialmente aquelas direcionadas à gestão de pessoas. 
Essas barreiras são relacionadas ao sistema americano de negócios - práticas tradicionais e pré-estabelecidas de $\mathrm{RH}$, precaução extrema quanto a movimentos sindicais valendo-se de práticas paternalistas, um sistema de remuneração detalhado e extremamente elaborado - e impedem muitas vezes que práticas inovadoras e bem sucedidas adotadas por subsidiárias possam ser implementadas nas matrizes (EDWARDS et al, 2005, LAWLER, et al, 2013).

Além dos aspectos relacionados à influência do país de origem e país de atividades, Edwards e Ferner (2002) observam que a gestão internacional de pessoas é influenciada por mais outras duas situações: a pressão pela integração internacional, a pressão para o alcance de certo grau de integração dentro das corporações multinacionais, uma vez que as diferenças entre os gostos dos consumidores de diferentes países estão diminuindo o que provoca a necessidade de interconexão entre muitas subsidiárias com operações similares; e, os efeitos da dominação, que dizem respeito ao fato de que historicamente as nações hegemônicas, a exemplo dos Estados Unidos, por seu desempenho econômico exemplar, acabam atraindo a atenção para suas práticas e formas organizacionais, as quais tendem a ser copiadas pelas corporações (EDWARDS e FERNER, 2002).

A pressão pela integração internacional afeta a gestão internacional de pessoas quando são criadas estruturas internacionais de gestão. A transferência de práticas e aprendizado entre subsidiárias é estimulada e as subsidiárias com desempenhos inferiores são pressionadas a adotarem as melhores práticas inspiradas por aquelas com desempenho superior. Além disso, os efeitos da dominação fazem com que as multinacionais originárias de países hegemônicos distribuam as práticas de sucesso para suas subsidiárias e, aquelas que possuem subsidiárias nesses busquem através delas essas melhores práticas e disseminem para a organização
(EDWARDS e FERNER, 2002). Mais recentemente, entretanto, práticas de inovação reversa mostram que em países emergentes, por vezes, a inovação tem origem na subsidiária (ZESCHKY et al, 2014; FENGXIA E SHAOMING, 2013; LEAVY, 2014; BORINI et al, 2012).

Outro aspecto importante balizador da gestão internacional de pessoas destacado por Schuler, Dowling e De Cieri (1993) é o grau de experiência internacional da organização. $\mathrm{O}$ papel do RH corporativo e suas práticas, bem como a atitude da matriz com a subsidiária estão intimamente ligados ao enfoque estratégico de internacionalização da empresa. As multinacionais internacionalizadas que buscam somente a exploração de recursos como mão-de-obra barata e/ou recursos materiais, certamente não irão apoiar uma gestão estratégica de recursos humanos em suas operações internacionais.

\section{Procedimentos Metodológicos}

Considerando-se o caráter investigativo do presente estudo que prioriza a profundidade na análise $\mathrm{e}$ compreensão de uma realidade complexa, decidiu-se pela utilização de uma metodologia qualitativa. As pesquisas qualitativas permitem contato direto com o objeto de estudo e resultam em aumento de compreensão, expansão de conhecimento, identificação de atitudes e comportamentos, exploração de distintas motivações, além de facilitar a análise dos dados (COOPER e SCHINDLER, 2003; BITENCOURT, 2001, FLICK, 2004; GODOY et al, 2006).

Nesta pesquisa buscou-se analisar a relação entre matriz e subsidiárias de organizações multinacionais com foco na gestão de RH. Para tanto, utilizou-se o método qualitativo de estudo de caso, que, para Yin (1994), é a estratégia de pesquisa mais adequada quando se deseja compreender um evento contemporâneo, a partir de proposições teóricas, que conduzam à coleta e análise dos dados, 
privilegiando a compreensão profunda de um determinado contexto.

$\mathrm{O}$ estudo de caso foi realizado em uma organização multinacional de origem norte-americana com foco na subsidiária brasileira e na unidade administrativa da América Latina. A escolha por essa organização orientou-se pelo seu reconhecimento internacional em seu segmento de atuação e pelo fato de as corporações norte-americanas serem caracterizadas por gerir de modo peculiar suas operações internacionais. Destaca-se, também, o período da coleta de dados, que aconteceu entre os meses de abril e maio de 2008, quando um novo sistema de gestão de recursos humanos estava sendo implementado na subsidiária brasileira, fato este influenciou a padronização das práticas de gestão de pessoas a partir do modelo exportado da matriz americana. Portanto, por ocasião de mudança no sistema é possível perceber mais nitidamente algumas transformações nas práticas e rotinas da organização e a flexibilidade que a subsidiária teria para se adaptar ou criar práticas inspiradas na cultura nacional ou organizacional.

As técnicas de coleta de dados utilizadas para a realização do estudo de caso foram: entrevistas semi-estruturadas em profundidade com gestores e colaboradores das duas unidades estudadas; análise de documentos e publicações relevantes disponibilizados pela organização; e pesquisa de dados nos websites da corporação e da subsidiária brasileira.

As entrevistas, num total de sete, foram realizadas com pessoas-chave da gestão geral e da área de recursos humanos da subsidiária e da unidade administrativa da América Latina, por se entender que elas seriam as fontes relevantes de informações para o estudo.

Realizou-se entrevistas com: gestor de RH da subsidiária brasileira; gestor corporativo de RH para América Latina; gestor geral da subsidiária brasileira; gestor industrial da subsidiária (participou do processo de internacionalização da corporação) e três profissionais de $\mathrm{RH}$ da subsidiária (que mantêm contato a matriz corporativa). Foram coletadas, também, informações dos seguintes documentos disponibilizados pela organização: livro de registros históricos da subsidiária brasileira e código de ética corporativo. Além disso, informações gerais da corporação e da subsidiária, disponíveis nas páginas das empresas na Internet, foram utilizadas como apoio às demais técnicas, permitindo a triangulação dos dados.

$\mathrm{Na}$ etapa de análise de dados utilizou-se a análise de conteúdo, estratégia que visa tornar objetivo o conteúdo das entrevistas em profundidade. Esta análise pode ser entendida como um conjunto de técnicas de análise de comunicação, que visam obter indicadores que permitam a inferência de conhecimentos relativos às condições às mensagens (BARDIN, 1977, FLICK, 2004; GODOY et al, 2006).

Neste sentido, para responder aos objetivos do estudo, com base nos aspectos teóricos já desenvolvidos, foram definidas as seguintes categorias de análise da pesquisa: internacionalização da corporação; modelo de gestão internacional da corporação; papel da subsidiária; transferência de práticas de gestão na corporação; gestão internacional estratégica de recursos humanos. No quadro abaixo (quadro 2), que combina aspectos teóricos e práticos, estão apresentadas as categorias de análise da pesquisa correspondentes ao tema do estudo, bem como as técnicas de coleta de dados utilizadas para a busca dessas informações. 


\begin{tabular}{|c|c|c|c|}
\hline CATEGORIAS & AUTORES & SUBCATEGORIAS & COLETA DE DADOS \\
\hline \multicolumn{4}{|c|}{ Organizações Multinacionais e suas Subsidiárias } \\
\hline \multirow{4}{*}{$\begin{array}{l}\text { Internacionalização } \\
\text { da corporação }\end{array}$} & \multirow{2}{*}{$\begin{array}{l}\text { Rocha e Almeida } \\
(1994) \\
\text { Carneiro et al (2011) }\end{array}$} & $\begin{array}{l}\text { Motivos da } \\
\text { internacionalização da } \\
\text { matriz }\end{array}$ & $\begin{array}{l}\text { - Entrevista com: gestor corporativo de } \\
\text { RH na América Latina, gestor industrial da } \\
\text { subsidiária e gestor geral da subsidiária } \\
\text { - Análise registros históricos }\end{array}$ \\
\hline & & $\begin{array}{l}\text { Estratégia de } \\
\text { internacionalização da } \\
\text { matriz }\end{array}$ & $\begin{array}{l}\text { - Entrevista com: gestor corporativo de } \\
\text { RH na América Latina } \\
\text { - Análise registros históricos }\end{array}$ \\
\hline & \multirow{2}{*}{$\begin{array}{l}\text { Vasconcelos,Caldas e } \\
\text { Wood Jr. (2004) } \\
\text { Caldas e Tonelli } \\
\text { (2011) } \\
\text { Rondinelli e Black } \\
\text { (2000) } \\
\text { Ramsey et al, } 2012\end{array}$} & $\begin{array}{l}\text { Processo de } \\
\text { fusão/aquisição da } \\
\text { subsidiária }\end{array}$ & $\begin{array}{l}\text { - Entrevista com: gestor corporativo de } \\
\text { RH na América Latina e gestor geral da } \\
\text { subsidiária } \\
\text { - Análise registros históricos } \\
\end{array}$ \\
\hline & & $\begin{array}{l}\text { Conseqüências da } \\
\text { fusão/aquisição para a } \\
\text { subsidiária }\end{array}$ & $\begin{array}{l}\text { - Entrevista com: gestor geral da } \\
\text { subsidiária e gestor industrial da } \\
\text { subsidiária }\end{array}$ \\
\hline \multirow{2}{*}{$\begin{array}{l}\text { Modelo de gestão } \\
\text { internacional da } \\
\text { corporação }\end{array}$} & \multirow{2}{*}{$\begin{array}{l}\text { Bartlett e Ghoshal } \\
(1986,1992,1998) \\
\text { Mazmania } \text { et al, } \\
2013 \\
\text { Andersson et al } \\
(2001)\end{array}$} & $\begin{array}{l}\text { Características do } \\
\text { modelo de gestão } \\
\text { utilizado pela } \\
\text { corporação }\end{array}$ & $\begin{array}{l}\text { - Entrevista com: gestor corporativo de } \\
\text { RH na América Latina e gestor da } \\
\text { subsidiária }\end{array}$ \\
\hline & & $\begin{array}{l}\text { Utiliza modelo } \\
\text { transnacional? }\end{array}$ & $\begin{array}{l}\text { - Entrevista com: gestor corporativo de } \\
\text { RH na América Latina e com gestor geral } \\
\text { da subsidiária }\end{array}$ \\
\hline \multirow{3}{*}{$\begin{array}{l}\text { Papel da subsidiária } \\
\text { na corporação }\end{array}$} & \multirow{3}{*}{$\begin{array}{l}\text { Bartlett e Ghoshal } \\
(1986,1992) \\
\text { Birkinshaw e } \\
\text { Morrison (1995) } \\
\text { Borini et al (2001) } \\
\text { D'cruz (1986) } \\
\text { Jarillo e Martinez } \\
(1990) \\
\text { Roth e Morrison } \\
(1992) \\
\text { Mazmania et al, } \\
\text { 2013 } \\
\text { Andersson et al } \\
(2001)\end{array}$} & $\begin{array}{l}\text { Papel desempenhado } \\
\text { pela subsidiária }\end{array}$ & $\begin{array}{l}\text { - Entrevista com: gestor corporativo de } \\
\text { RH na América Latina e gestor geral da } \\
\text { subsidiária }\end{array}$ \\
\hline & & $\begin{array}{l}\text { Características da } \\
\text { atuação da subsidiária }\end{array}$ & $\begin{array}{l}\text { - Entrevista com: gestor geral da } \\
\text { subsidiária e gestor corporativo de RH na } \\
\text { América Latina } \\
\text { - Análise documental }\end{array}$ \\
\hline & & $\begin{array}{l}\text { Importância estratégica } \\
\text { da subsidiária }\end{array}$ & $\begin{array}{l}\text { - Entrevista com: gestor corporativo de } \\
\text { RH na América Latina }\end{array}$ \\
\hline $\begin{array}{l}\text { Disseminação de } \\
\text { práticas na } \\
\text { corporação }\end{array}$ & Saka (2002) & $\begin{array}{l}\text { Transferência de } \\
\text { práticas dentro da } \\
\text { corporação }\end{array}$ & $\begin{array}{l}\text { - Entrevista com: gestor de RH da } \\
\text { subsidiária, gestor corporativo de RH na } \\
\text { América Latina, gestor geral da subsidiária } \\
\text { e profissionais de RH da subsidiária } \\
\text { - Análise documental }\end{array}$ \\
\hline \multicolumn{4}{|c|}{ Gestão Internacional Estratégica de Recursos Humanos } \\
\hline \multirow[t]{2}{*}{$\begin{array}{l}\text { Gestão Internacional } \\
\text { Estratégica de } \\
\text { Recursos Humanos }\end{array}$} & $\begin{array}{l}\text { Albuquerque e } \\
\text { Bosquetti (2005) } \\
\text { Albuquerque e } \\
\text { Fischer (2001) } \\
\text { Silva e Fleury, } \\
(2013) \\
\text { Miranda e } \\
\text { Mendez (2012) }\end{array}$ & $\begin{array}{l}\text { Atribuições dos } \\
\text { profissionais de RH da } \\
\text { subsidiária }\end{array}$ & $\begin{array}{l}\text { - Entrevista com: profissionais de RH da } \\
\text { subsidiária, gestor corporativo de RH na } \\
\text { América Latina e gestor de RH da } \\
\text { subsidiária }\end{array}$ \\
\hline & $\begin{array}{l}\text { Ulrich (2000) } \\
\text { Silva e Fleury, } \\
(2013)\end{array}$ & $\begin{array}{l}\text { Papéis desempenhados } \\
\text { pelo RH da subsidiária }\end{array}$ & $\begin{array}{l}\text { - Entrevista com: gestor da subsidiária, } \\
\text { gestor de RH da subsidiária e profissionais } \\
\text { de RH da subsidiária }\end{array}$ \\
\hline
\end{tabular}

Revista de Negócios, ISSN 1980-4431, Blumenau, Brasil, v. 19, n. 2, p. 36-61, Abril/Junho de 2014. 
Análise da relação entre subsidiária brasileira e matriz de corporação norte-americana com foco na gestão de RH

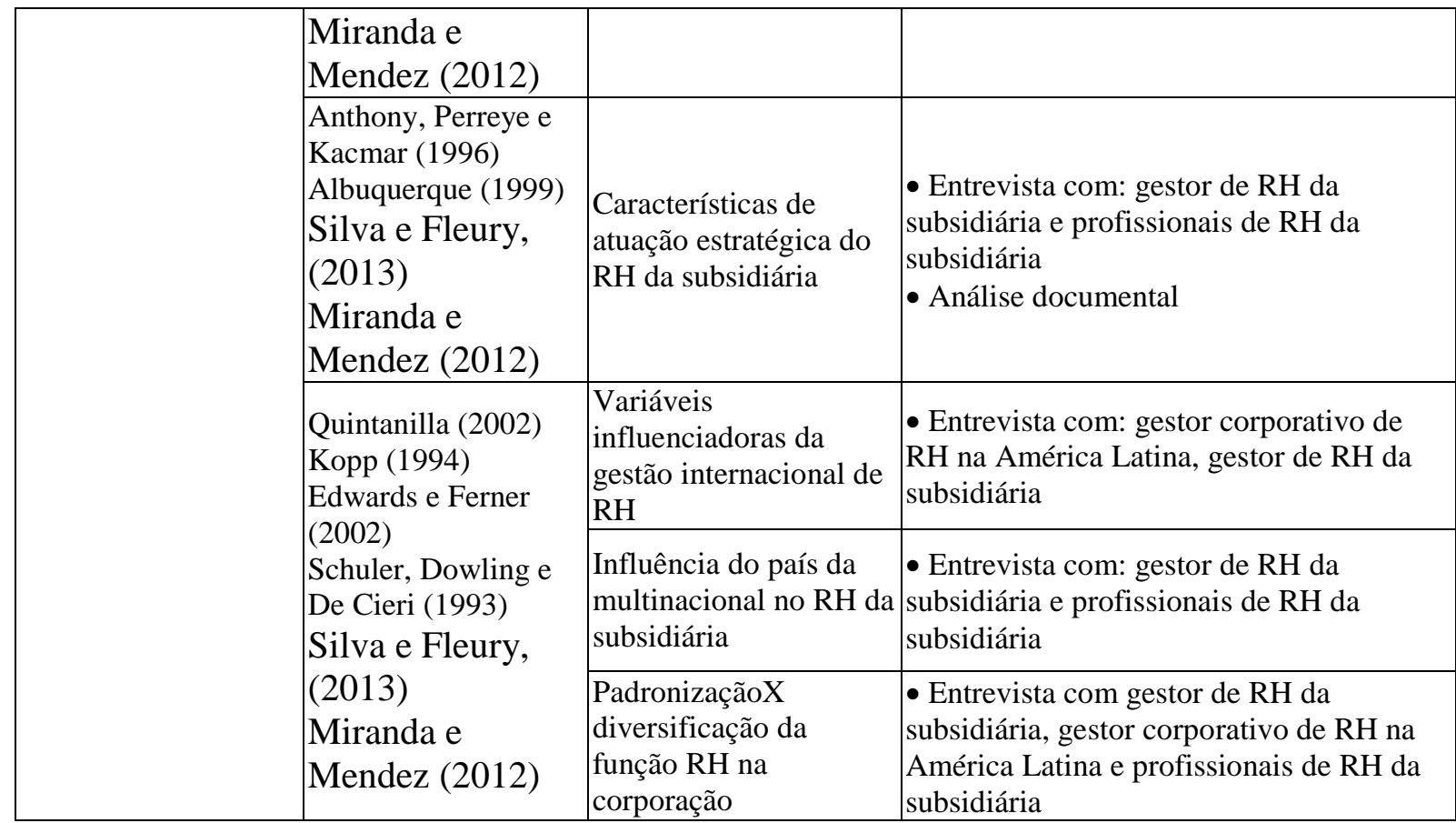

Quadro 2: Categorias de análise e técnicas de coleta de dados

Fonte: Elaborado pelas autoras

\section{Apresentação e Análise dos dados}

$O$ estudo foi realizado em uma corporação norte-americana de capital aberto, líder mundial em climatização, que produz aparelhos residenciais condicionadores de ar, refrigeradores comerciais, centrais residenciais e comerciais de ar condicionado e aparelhos de ar condicionado para veículos. A corporação possui subsidiárias em 67 países e comercializa seus produtos em mais de 170, contando com 45 mil colaboradores e um faturamento anual que ultrapassa os US\$ 9 bilhões.

As operações da corporação estão divididas em operação norte-americana, operação latino-americana, Europa transcontinental e operação Ásia - Pacífico - Oceania. Em cada região, as operações são geridas por um centro administrativo responsável pelas unidades que a compõem.

A corporação estudada faz parte de um grande grupo mundial, com $220 \mathrm{mil}$ colaboradores, que, além de climatização, atua nos segmentos de aviação; elevadores e escadas rolantes; sistemas de construção; aeroespacial e energia. Esse grupo mundial possui como importantes clientes exércitos e agências espaciais, característica essa que demanda excelência em todos os processos de todas as empresas que o compõem, devido ao alto nível de exigência desses clientes.

O foco da pesquisa foi a subsidiária brasileira da corporação, que na ocasião contava com aproximadamente 1000 colaboradores. A unidade brasileira estudada faz parte das operações latinoamericanas da unidade de negócios de aparelhos residenciais e comerciais leves da corporação. A gestão de suas atividades está dividida em duas grandes diretorias: a de operações e a comercial. A diretoria de operações é responsável pelas áreas de recursos humanos, finanças, qualidade, pós-vendas, garantia, engenharia industrial, engenharia de produto, compras, manufatura e tecnologia da informação; enquanto que a diretoria comercial responde pelas atividades relacionadas ao marketing, vendas e distribuição. A identidade da organização estudada, por restrições dela mesma, será preservada. 


\subsection{A Internacionalização da Corporação}

A corporação norte-americana expandiu suas atividades globalmente principalmente nas décadas de 70 e 80 não somente através da comercialização de seus produtos em outros países, mas também por meio da descentralização da produção com a aquisição de empresas de climatização em diferentes continentes. A descentralização da produção foi justificada pelas peculiaridades existentes nos diferentes mercados mundiais de climatização, as quais podiam ser mais bem supridas com a instalação da empresa no local de atuação ao invés da simples exportação para esses locais.

A inserção da corporação no mercado brasileiro aconteceu no ano de 1973, com a abertura de uma pequena subsidiária no Rio de Janeiro. Porém, por o Brasil ser um grande mercado, com potencial de crescimento, a corporação norte-americana pretendia aumentar sua penetração no país. Para isso, optou por adquirir uma empresa já existente a fim de possuir parceiros que lhe ajudasse na compreensão da cultura do país e do sistema de negócios nacional. Este fato é apontado por Vasconcelos, Caldas e Wood Jr. (2004), e também por Ramsey et al (2012), como muito comum em países emergentes, nos quais organizações multinacionais buscam aumentar sua participação de mercado através da compra de empresas locais.

Assim, dez anos depois de sua vinda para o Brasil, em 1983, através de uma joint venture, a corporação norteamericana adquiriu inicialmente $51 \%$ e depois passou a deter $80 \%$ da maior fabricante brasileira de climatização desde aquela época, localizada na região sul do país.

A empresa brasileira adquirida possuía uma tradição de quase 50 anos, com marca forte no mercado doméstico, saúde financeira, processos de produção modernos, um corpo de trabalho e administrativo experiente e dedicado, detinha uma expertise em uma determinada linha de produtos - aparelhos residenciais de janela - e precisava de apoio para penetrar no mercado internacional. Já a corporação norte-americana era especialista em outra linha de produtos aparelhos residenciais de grande porte -, possuía estabilidade financeira e pretendia penetrar no mercado brasileiro. Dessa união e das outras que a corporação norteamericana realizou na mesma época, surgiu a empresa líder mundial em climatização.

O processo de aquisição da subsidiária brasileira, ocorrido em 1983, foi marcado principalmente pela disseminação da cultura corporativa da matriz norte-americana para a recém adquirida. Inicialmente, a corporação trouxe alguns gestores norte-americanos, por um curto período, para que disseminassem as políticas da corporação para a subsidiária e compreendessem a dinâmica brasileira de operação. Vieram alguns colaboradores também, principalmente para a área financeira, pois essa área principalmente precisou passar a atuar dentro dos padrões norte-americanos. A subsidiária passou, então, a ter que realizar reportes diretos de suas atividades para a matriz corporativa e atuar dentro do sistema de negócios norte-americano.

No caso específico da aquisição da subsidiária brasileira, a corporação sempre prezou por uma forte permanência dos gestores locais, por eles possuírem competências e experiência na gestão do complexo sistema de produção e distribuição brasileiro, dado o tamanho do mercado e a diversidade de produtos comercializados.

Passado o período inicial de intercâmbio de culturas, a gestão da subsidiária vem sendo executada por gestores locais, com algumas exceções de gestores que vieram da Argentina para o Brasil. Não existem hoje atuando na empresa expatriados norte-americanos da matriz. Pelo contrário, a subsidiária brasileira envia colaboradores, 
principalmente de engenharia - para outras unidades da corporação por sua expertise em determinadas tecnologias.

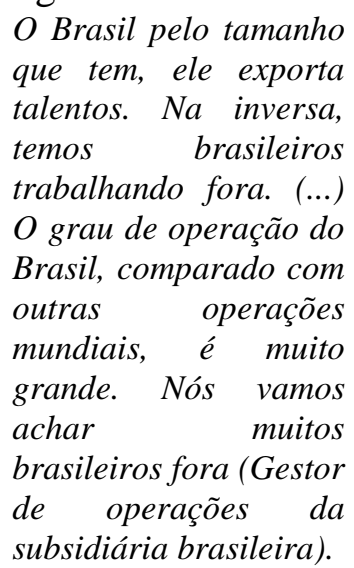

Em relação às consequiências do processo de fusão/aquisição, a união à corporação norte-americana gerou, num primeiro momento, nos colaboradores da subsidiária algum descontentamento e resistência, mas essa situação foi rapidamente desfeita, quando do aumento do volume de produção e de novos produtos ocasionados pela parceria. Verifica-se, portanto, que não se salientaram nesse caso as conseqüências negativas comuns em fusões/aquisições identificadas por Caldas e Tonelli (2011) um clima grupal agressivo, perdas identitárias e de memória e sentimentos de frustração que provocam o desgaste emocional.

Percebe-se, assim sendo, que o processo de fusão/aquisição da empresa brasileira pela corporação norte-americana foi bem gerido. Isso porque se evitaram demissões em massa e se adotou uma atitude de dignidade e respeito com os funcionários da empresa adquirida desenvolvida, fatores destacados por Vasconcelos, Caldas e Wood Jr. (2004) como essenciais para o sucesso de fusões/aquisições.

Os gestores da subsidiária, da mesma forma, avaliam que o processo de incorporação da subsidiária pela corporação foi bem planejado e executado, pois é uma parceria que tem dado excelentes resultados já por mais de 30 anos e a corporação continua realizando investimentos na subsidiária para a expansão de sua planta produtiva.

\subsection{O Modelo de Gestão Internacional da Corporação}

A corporação estudada realiza a gestão de suas operações internacionais com base em dois grandes eixos: o administrativo e o funcional. Enquanto que os gestores das subsidiárias se reportam administrativamente à matriz corporativa, existe um reporte funcional que é realizado diretamente dos colaboradores funcionais das subsidiárias para a matriz corporativa, além de seu reporte administrativo aos gestores locais. O setor financeiro da subsidiária brasileira, por exemplo, além de reportar-se ao gestor geral do Brasil, reporta-se também diretamente a colaboradores da matriz corporativa. Esse reporte funcional, diretamente com a matriz corporativa, acontece nas áreas de engenharia, recursos humanos, finanças e supply chain management.

O grupo mundial, do qual a corporação faz parte, presta serviços para grandes clientes, muito exigentes, como agências espaciais e exércitos, o que demanda extrema organização pelo alto nível de exigência desses clientes. Esse grupo mundial, conseqüentemente a corporação norte-americana e sua subsidiária brasileira, caracterizam-se, então, por ter uma visão processual, possuindo muito bem descritos, definidos e detalhados todos seus processos.

Em todas as unidades de todas as corporações que compõem o grupo, as políticas de qualidade, meio ambiente, saúde, segurança, educação de colaboradores, gestão de processos e recursos humanos são as mesmas, a fim de que padrões de desempenho e atuação sejam os melhores possíveis.

Em se tratando da corporação norte-americana, ela desenvolveu e implantou no ano de 2000 um sistema de gestão próprio que padronizou a gestão em todas as subsidiárias por toda a corporação. Trata-se de um conjunto de ferramentas de 
diagnóstico, solução de problemas e avaliação de desempenho que promova a excelência competitiva em todos os processos para as várias unidades da corporação. $\mathrm{O}$ processo inicia com a definição dos objetivos estratégicos da corporação, das subsidiárias e de suas áreas para que depois sejam traçadas as ações necessárias para atingir esses objetivos e seus resultados sejam medidos com métricas previamente definidas.

Através desse sistema, que possui uma base forte de medição, a corporação é capaz de vislumbrar não só o desempenho de suas unidades, mas também de cada uma das áreas da empresa, chamadas de células. A utilização desse tipo de controle das subsidiárias é apontada por Ferner e Quintanilla (1998) e por Edwards et al (2013) como característica das organizações norte-americanas, que preferem modos de controle das subsidiárias mais burocráticos a sociais, o que se reflete através da predominância de políticas formais e globais, como, por exemplo, esse sistema de gestão da corporação (FERNER e QUINTANILLA, 1998).

Em suma, analisando-se o modo como a corporação gere suas mais de 60 unidades internacionais, percebe-se que a corporação estudada adota a estratégia transnacional, proposta por Bartlett e Ghoshal $(1992,1998)$, pois ela atua como uma rede. Cada subsidiária contribui de forma diferenciada com a corporação, na área de negócio, mercado ou linha de produtos em que atua. Ao mesmo tempo em que cada subsidiária contribui de modo singular, isso não impede que todas as unidades caminhem em conjunto no atingimento dos objetivos corporativos, quando são disponibilizadas ferramentas corporativas de gestão e avaliação de desempenho muito completas.

Esse modelo de gestão da corporação, segundo os entrevistados, está relacionado ao seu grau de experiência internacional, uma vez que há muito tempo a companhia é bem maior fora dos Estados
Unidos, do que dentro dele, sendo, então, sua capacidade de gerir internacionalmente muito bem desenvolvida.

\subsection{O Papel da Subsidiária Brasileira}

Como na estratégia transnacional, utilizada pela corporação estudada, cada subsidiária da corporação possui um papel e uma contribuição diferente, cabe analisar qual o papel e relevância estratégica da subsidiária brasileira para a corporação norte-americana.

A avaliação do desempenho das subsidiárias é rigorosamente realizada através das métricas do sistema de gestão da corporação, as quais avaliam resultados de toda natureza. As subsidiárias são avaliadas, então, não conforme seu nível de importância na corporação, mas sim conforme sua busca em atingir os padrões corporativos de desempenho. Existe inclusive na corporação uma certificação oficial dada às subsidiárias que vão desde o nível bronze, até prata e ouro. A subsidiária brasileira possui nível prata e está buscando nesse ano o nível ouro, que somente quatro unidades no mundo possuem.

$$
\begin{aligned}
& \text { Existe uma } \\
& \text { classificação de ouro, } \\
& \text { prata e bronze, de } \\
& \text { desempenho das } \\
& \text { unidades no que passa } \\
& \text { desde o desempenho } \\
& \text { operacional, até as } \\
& \text { práticas de gestão e } \\
& \text { inclui também a } \\
& \text { gestão de pessoas } \\
& \text { (Gestor corporativo } \\
& \text { de RH da América } \\
& \text { Latina). }
\end{aligned}
$$

A subsidiária brasileira possui na corporação, desde sua aquisição, uma grande relevância. Isso se deve a três principais fatos: a importância do Brasil como mercado - é o $4^{\circ}$ maior da corporação -; a participação de mercado da subsidiária e o conhecimento existente na subsidiária, principalmente em engenharia, uma vez que a subsidiária é o Lead Design Center mundial para um tipo de produto, atendendo ao mundo inteiro. 
Em termos de reconhecimento oficial, a subsidiária já recebeu da corporação e do grupo mundial que a detém vários prêmios e certificações. $\mathrm{Na}$ década de 90, década da qualidade total, um grupo de CCQ (Círculo de Controle da Qualidade) da subsidiária brasileira venceu uma disputa com todas as unidades da América Latina. Em 1998, a empresa alcançou $82 \%$ de conformidade em meio ambiente, saúde e segurança (MASS), nível inédito dentre as empresas do grupo mundial. Em 1999, a subsidiária recebeu o Troféu do Presidente da corporação na categoria MASS. Em 2000, a unidade brasileira recebeu um prêmio do grupo mundial em Excelência e Inovação em Meio Ambiente. Em 2000, 2001 e 2004, a subsidiária recebeu da corporação o Prêmio do Presidente conferido por sua Excelência e Efetividade no Trato das Questões referentes à Satisfação dos Funcionários. Mais recentemente, a unidade brasileira tornou-se benchmark corporativo por estar há 21 milhões de horas sem acidentes graves de trabalho.

Então, se comparadas suas características de atuação e desempenho e relevância na corporação às tipologias sobre papéis de subsidiárias, a subsidiária brasileira é considerada uma subsidiária com mandato mundial, uma vez que possui responsabilidade global por uma linha de produtos e cria competências para a corporação por reunir capacidades e recursos estratégicos aliados a um mercado estrategicamente importante (BARTLETT e GHOSHAL, 1986; BARTLETT e GHOSHAL, 1992; BIRKINSHAW e MORRISON, 1995; BORINI et al, 2001; D'CRUZ, 1986; JARILLO e MARTINEZ, 1990; ROTH e MORRISON, 1992, DOUTHITT e MONDORE, 2013).

\subsection{Transferência de práticas de gestão na corporação}

$\mathrm{Na}$ corporação estudada, realiza-se uma divisão clara entre políticas e práticas. As políticas são definidas corporativamente, repassadas para as unidades e seu seguimento é prerrogativa, pois elas delineiam a gestão em todas as áreas das unidades. Já as práticas, estas são menos padronizadas, uma vez que as subsidiárias têm autonomia para sua criação, desde que elas venham ao encontro das políticas corporativas e que não existam ainda padrões internacionais. Existe, porém, também a transferência e padronização de práticas vistas como as melhores para as unidades, exigindo-se que certas operações sejam realizadas de forma padrão em nível mundial.

Existe uma série de
ferramentas,
procedimentos
processos que a gente
recebe da corporação
$e$ tem que seguir.
Porém, existe uma
infinidader de
processos que a gente
tem total liberdade
para atuar porque não
existe uma definição
internacional (Gerente
de RH da subsidiária).
na organização

Esse cenário na organização
da corresponde às afirmações de Birkinshaw e Morrinson (1995), os quais identificaram que quanto mais forte a relação de trabalho e o grau de integração normativo entre matriz e subsidiárias, menor a chance da subsidiária trabalhar de modo não alinhado às estratégias corporativas e, por isso, as corporações buscam disseminar as melhores práticas para todas suas subsidiárias.

A transferência de práticas da matriz corporativa para as unidades em todo o mundo acontece sempre de modo planejado, uma vez que ocorre a definição de etapas e prazos para sua implementação, na qual irão trabalhar representantes locais da área em que será implantada a nova prática. Na matriz permanece sempre uma equipe de suporte responsável por apoiar a implantação nas unidades corporativas. Um exemplo recente de transferência de prática para a subsidiária brasileira foi a implantação da ferramenta corporativa de avaliação de desempenho individual online. 


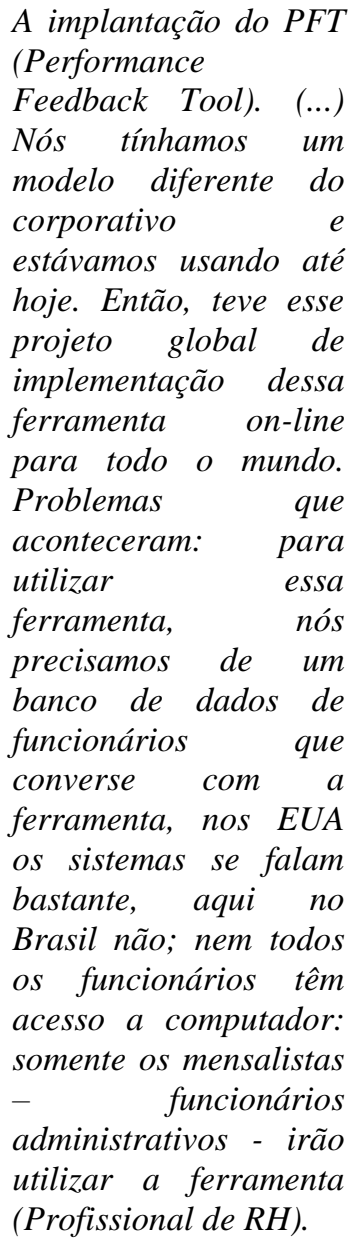

A subsidiária, apesar de ter sido incorporada pela multinacional há 30 anos, o que poderia significar boa aderência às práticas corporativas, era conhecida no passado por posicionar-se contrária quando determinada prática ou ferramenta vinda da corporação não se encaixava perfeitamente ao contexto local, seja pela legislação ou cultura local. Em relação à área de recursos humanos da subsidiária, a corporação optou recentemente por trocar seu sistema de gestão, redefinindo estrutura e funções dentro da área, bem como, revendo todos os processos com objetivo de gerar sinergia e aderência à corporação, minimizando resistências.

Ainda no tocante à transferência de práticas, como já mencionado, a corporação promove formalmente e também ocorre informalmente $\mathrm{o}$ intercâmbio de melhores práticas entre suas unidades. $\mathrm{Na}$ área de recursos humanos, por exemplo, existem fóruns e grupos globais para que sejam apresentadas as práticas de sucesso desenvolvidas nas unidades.

Recentemente rum
fórum de recursos
humanos, o $\begin{array}{r}\text { Canadá } \\ \text { apresentou }\end{array} \quad$ um
Programa de
Integração de Novos
Empregados e isso foi
considerado uma best
practice e que se
disponibiliza para ser
utilizado por todas as
outras unidades
(Gestor corporativo de
RH da América
Latina).
então, que

Percebe-se, então, que a corporação, além de definir políticas corporativas em todas as áreas, busca uniformizar suas práticas em todo o mundo. Isso se dá através da definição de algumas práticas por parte da matriz e do estímulo, através da criação de momentos de troca - fóruns/grupos globais de discussão, para que as unidades possam mostrar umas para as outras suas práticas de sucesso.

Assim sendo, não se pode dizer que a corporação possua fortes barreiras à difusão reversa, bem pelo contrário, essa difusão é estimulada. $\mathrm{O}$ que vai contra as observações de Edwards et al (2005), quando $o$ autor caracteriza as multinacionais norte-americanas como fechadas à difusão reversa, ou seja, a difusão para a matriz de práticas desenvolvidas em subsidiárias estrangeiras, especialmente aquelas direcionadas à gestão de pessoas. Contudo, ainda não se pode afirmar que as práticas são inovadoras ou incorporadas pela matriz.

\subsection{Gestão Internacional Estratégica de RH na Subsidiária Brasileira}

Uma vez realizada a compreensão das características de gestão da corporação estudada, do modo que ocorre a transferência das práticas de gestão e das características de atuação da subsidiária brasileira, pode-se, então, analisar como se desenvolve a gestão de RH em uma 
subsidiária de uma organização multinacional.

A área de recursos humanos da subsidiária brasileira é centralizada na região sul do país com alguns colaboradores no sudeste e norte. Na sede, a área conta com quatro células/especialidades: recrutamento e seleção, remuneração e benefícios, administração de pessoal e folha de pagamento, e treinamento e desenvolvimento. A área é responsável também pela administração patrimonial e dos terceiros da empresa.

Atuam na sede do RH três especialistas, dois analistas e dois estagiários, além de terceiros responsáveis pela folha de pagamento. Na região sudeste há um coordenador e um estagiário de recursos humanos que atuam como consultores generalistas para as áreas da estrutura comercial lá instalada. Na região norte, onde há uma unidade produtiva, atuam um coordenador, um assistente de seleção e um analista de recursos humanos. Os especialistas e coordenadores executam, além de sua especialidade, a função de consultores internos generalistas de RH para todas as áreas da empresa.

A gestão de $\mathrm{RH}$ da subsidiária é coordenada por uma diretoria corporativa de recursos humanos da América Latina e pela diretoria geral da subsidiária. $\mathrm{O}$ gestor de RH da subsidiária reporta-se, portanto, funcional e administrativamente a essas duas áreas. Além desses dois reportes, a área de RH realiza em algumas atividades, através do envio de relatórios e informações, um reporte direto à vicepresidência corporativa de recursos humanos.

A área desempenha, dadas suas características de atuação, papel estratégico na organização, uma vez que, além de executar as tarefas tradicionais da área, participa das principais decisões da empresa que incluem, por exemplo, projetos de mudança e redesenho de estrutura. Essas atividades alcançam alguns dos novos papéis do $\mathrm{RH}$ propostos por
Ulrich (1998), Millan (2011), Ogbonnaya et al (2012), observando que o RH deve ser: gestor das estratégias de recursos humanos; gestor da transformação e mudança; gestor da infra-estrutura da empresa; e gestor da contribuição dos funcionários.

O objetivo estratégico da área, definido pela corporação e pela subsidiária, é atrair, desenvolver e reter pessoas que propiciem a continuidade do negócio, conforme seu gestor e profissionais entrevistados. Características essas que vão ao encontro das novas atribuições dos profissionais de RH apontadas por Albuquerque e Bosquetti (2005) e por Douthitt e Mondore (2013): preocupar-se mais intensamente com a identificação, captação e retenção de talentos bem como a criação de um ambiente aberto à mudança e aprendizagem. Além disso, a abordagem estratégica de $\mathrm{RH}$ da empresa pode ser vislumbrada quando ela realiza trabalhos permanentes de desenvolvimento de lideranças, coaching com gestores, seleção de pessoas e avaliação de desempenho por competências e consultoria interna de $\mathrm{RH}$.

Igualmente, na organização estudada, percebe-se com clareza o quão peculiar é a gestão de RH em multinacionais, mais especificamente em subsidiárias dessas corporações. No caso da subsidiária brasileira, identificou-se como principal desafio da gestão de RH o fato de que nessas empresas é necessário seguir o modelo corporativo ao mesmo tempo em que tem de ser levadas em conta as características locais. Enquanto a corporação demanda da subsidiária que políticas e determinações sejam seguidas, os gestores locais das áreas as questionam. Isso faz com que a gestão de $\mathrm{RH}$ da subsidiária tenha que possuir um posicionamento firme e flexível ao mesmo tempo a fim de conseguir atender a ambos os lados.

Entre as principais variáveis que influenciam a gestão de RH na subsidiária, foi destacado por seu gestor e profissionais 
que o sistema de negócios do país de origem da multinacional, no caso os Estados Unidos, e a cultura e legislação do país de operações, Brasil, são os fatores que mais a influenciam. O que vai ao encontro ao modelo de Quintanilla (2002) que aponta como principais influenciadores o sistema de nacional de negócios do país de origem da corporação; a cultura do país de atividade; os recursos e capacidades gerenciais da subsidiária; e as características do setor em que a empresa atua.

O sistema de negócios dos Estados Unidos é caracterizado pelos entrevistados como sendo bem diferente do brasileiro. A corporação estudada é caracterizada como extremamente processual, onde todas as práticas de gestão estão muito bem descritas e seu seguimento é primordial. Além disso, as organizações norteamericanas costumam ser menos flexíveis que as brasileiras ou européias, seu foco é forte em resultados financeiro-econômicos de curto prazo, a tomada de decisão é baseada em históricos recentes, reestruturações são freqüentes, trabalha-se fortemente sob pressão, todas as ações na empresa são analisadas conforme seu impacto financeiro.

Mais especificamente na gestão de $\mathrm{RH}$, a corporação estudada, por ser de origem norte-americana, é apontada por priorizar suas atividades em remuneração e departamento de pessoal. Além disso, as políticas e algumas ferramentas de RH são padronizadas pelo mundo todo, formalizadas e regulamentadas como, por exemplo, o planejamento de carreira/sucessão dos gestores, a avaliação de desempenho individual, o programa de educação dos colaboradores, o planejamento salarial, o treinamento em ética, a gestão por competências e o programa de participação nos lucros.

Essas características vão ao encontro dos achados de Almond et al (2005) que afirma as corporações multinacionais norte-americanas tenderem a exportar formas organizacionais e métodos de gestão estabelecidos nos Estados Unidos para o mundo todo. Ferner et al (2004) e Lawler et al (2013) apontam, também, que essas organizações possuem sistemas de gestão de recursos humanos formalizados e centralizados.

Além da influência do país de origem da multinacional, a gestão de $\mathrm{RH}$ da subsidiária brasileira é afetada fortemente pela cultura e legislação de seu país. No tocante à cultura, na subsidiária brasileira são proporcionados alguns importantes benefícios, que nos Estados Unidos são considerados desnecessários, a exemplo de disponibilizar um automóvel para os gestores, o que no Brasil é visto como atrativo em uma organização. Em relação à legislação, a subsidiária tem de adotar algumas premissas diferentes das corporativas no que tange a remuneração, quando no Brasil, por exemplo, existe uma negociação coletiva de aumento salarial anual que nos Estados Unidos não ocorre. Situação essa já apontada por Quintanilla (2002).

A gestão de recursos humanos da subsidiária é influenciada ainda por dois outros fortes fatores, identificados por Edwards e Ferner (2002): a pressão pela integração internacional e os efeitos da dominação. A gestão de RH na subsidiária é influenciada pela pressão pela integração internacional, quando cada vez mais são criados programas e políticas corporativos de recursos humanos e sua autonomia vai diminuindo. Em relação aos efeitos da dominação, a subsidiária brasileira, apesar de estar em um país emergente, ainda consegue posicionar-se de forma a analisar e questionar as determinações vindas da matriz, por sua relevância estratégica dentro da corporação. Sua pequena representatividade em tamanho frente à corporação, porém, faz com que às vezes, ela tenha que deixar de lado suas ferramentas locais e aceitar as corporativas - como no caso da ferramenta de avaliação de desempenho individual, em que a subsidiária possuía uma local desenvolvida, mas que acabou sendo 
substituída pela corporativa, com a justificativa de maior facilidade de controle.

Percebe-se, assim, que existe na corporação estudada um forte movimento de padronização e formalização da gestão de recursos humanos, o que ocorre através da disseminação das práticas de sucesso para toda corporação e do desenho de políticas rigorosas, principalmente em remuneração, treinamento e avaliação de desempenho. A gestão de RH da subsidiária brasileira trabalha, portanto, no sentido de equilibrar as demandas da matriz corporativa e dos gestores locais.

\section{Considerações Finais}

Neste artigo estudou-se, a partir de um apanhado teórico sobre o tema, com a utilização do caso da subsidiária brasileira de uma corporação norte-americana, líder mundial em climatização, a relação entre matriz e subsidiárias em corporações multinacionais com foco na gestão de recursos humanos. A pesquisa compreendeu inicialmente a gestão geral da corporação estudada - sua internacionalização para o Brasil, seu modelo de gestão internacional, o papel da subsidiária brasileira na corporação e como se desenvolve a transferência de práticas na corporação -, o que serviu de base contextual para a posterior análise da gestão internacional estratégica de recursos humanos na subsidiária brasileira.

$\mathrm{Na}$ época da união da subsidiária à corporação, ela atraiu a atenção da norteamericana, que queria aumentar sua penetração no mercado brasileiro, por sua tradição e grande participação de mercado. A incorporação trouxe para a subsidiária as políticas e a cultura corporativas com muitas características do sistema de negócios americano, ao mesmo tempo em que se procurou respeitar a experiência administrativa e de operações local. Esse equilíbrio é considerado como fator-chave para o sucesso desse processo de fusão/aquisição.
A partir da compreensão de sua dinâmica de atividade, identificou-se a adoção da estratégia internacional por parte da corporação na gestão suas unidades internacionais, o que se deve, entre outros motivos, ao seu grau de experiência internacional que lhe confere grande capacidade de gestão de operações em outros países. Na corporação, a subsidiária brasileira, desde sua incorporação, é considerada uma subsidiária de mandato mundial, por sua relevância estratégica, uma vez que possui responsabilidade global por uma linha de produtos e reúne capacidades e recursos estratégicos aliados a um mercado estrategicamente importante.

Como características importantes da corporação estudada se pode verificar, também, que ela possui um modelo de gestão burocrático, uma vez que seus processos, áreas e unidades em todo o mundo são geridos através de um sistema corporativo, composto de ferramentas e métricas bem definidas e detalhadas, os quais visam a excelência competitiva. Além disso, percebeu-se que todas as políticas, inclusive algumas práticas e procedimentos, são definidos corporativamente e seu seguimento pelas subsidiárias é essencial. As políticas de qualidade, meio ambiente, saúde, segurança, educação de colaboradores, gestão de processos e recursos humanos são as mesmas, a fim de que padrões de desempenho e atuação sejam os melhores possíveis. Busca-se, também, na corporação a uniformização das principais práticas, quando algumas são definidas na matriz e disseminadas para todas as unidades e também são criados momentos de interação - fóruns/grupos globais de discussão - para que as subsidiárias e a matriz possam trocar entre si suas práticas de sucesso.

A gestão de RH na subsidiária brasileira desempenha, dadas suas características, papel estratégico na organização, uma vez que, além de executar as tarefas tradicionais da área, 
participa das principais decisões da empresa que incluem, por exemplo, projetos de mudança e redesenho de estrutura. Seu objetivo estratégico na empresa é atrair, desenvolver e reter pessoas que propiciem a continuidade do negócio. A abordagem estratégica de $\mathrm{RH}$ também é vislumbrada quando ela realiza trabalhos permanentes de desenvolvimento de lideranças, coaching com gestores, seleção de pessoas e avaliação de desempenho por competências e consultoria interna de RH.

Destacou-se na pesquisa que as características do sistema de negócios norte-americano e da legislação e cultura brasileiras são as variáveis que mais influenciam a gestão de RH na subsidiária. Como as estratégias de gestão de pessoas são definidas na matriz norte-americana e repassadas às subsidiárias, que realizam se necessário, somente pequenas alterações, as características do sistema de negócios norte-americano, que estão imbuídas nessas estratégias, acabam influenciando diretamente a função RH nas unidades da corporação. No tocante à influência da cultura brasileira, na subsidiária são proporcionados alguns importantes benefícios, que no Brasil são vistos como atrativos e nos Estados Unidos não possuem tanto valor, como, por exemplo, disponibilizar carros aos gestores. Em relação à legislação, a subsidiária tem de adotar algumas premissas diferentes das corporativas no que tange a remuneração, quando no Brasil, por exemplo, existe uma negociação coletiva de aumento salarial anual que nos Estados Unidos não ocorre.

Além disso, a gestão de recursos humanos da subsidiária é influenciada pela pressão para a integração internacional, quando são criados programas e políticas corporativos de recursos humanos e sua autonomia vai diminuindo. A subsidiária sofre os efeitos da dominação de países hegemônicos, porém em menor escala do que em outros países emergentes, uma vez a subsidiária brasileira consegue posicionar-se frente às determinações vindas da matriz por sua relevância estratégica na corporação.

Percebe-se, assim, a peculiaridade e complexidade da função RH em subsidiárias de organizações multinacionais pelo fato de que sua gestão deve atender ao mesmo tempo as demandas corporativas e locais. A área adota um posicionamento simultaneamente firme e flexível a fim de seguir as definições da matriz corporativa e atender às demandas locais, sofrendo influências do país de origem da multinacional e do país de operações da subsidiária.

Igualmente, os esforços em relação à melhoria da relação entre matriz e subsidiárias, bem como entre subsidiárias como, por exemplo, os fóruns/grupos globais de discussão na corporação estudada - são essenciais para a função RH possa, então, ser desempenhada de modo ideal nas organizações globais. Trata-se de um meio pelo qual, através do estímulo à interação, as subsidiárias e a própria matriz corporativa possam contribuir para o desenvolvimento da gestão de pessoas na corporação como um todo, apesar da centralização característica das corporações norte-americanas.

Por fim, a pesquisa trouxe à academia contribuições para o avanço dos estudos em gestão internacional de recursos humanos, uma vez que procurou compreender a gestão de RH em multinacionais como função dinâmica determinada pelo contexto organizacional e cultural da multinacional e da subsidiária. O estudo teve, porém, como limitação o fato de que, por restrições da empresa, não se teve acesso a informações da matriz corporativa, uma vez que foram coletados dados somente junto à subsidiária brasileira.

\section{Referências}

AGUZZOLI, R. L. Gestão de Pessoas Internacional: Como multinacionais brasileiras internacionalizam seus recursos humanos. Dissertação (Mestrado em 
Análise da relação entre subsidiária brasileira e matriz de corporação norte-americana com foco na gestão de RH

Administração) - Escola de Administração. Porto Alegre: Universidade Federal do Rio Grande do Sul, 2006.

AGUZZOLI, R. L. et al. Capacitar para Desenvolver: Como multinacionais estrangeiras no Brasil investem em sua mão-de-obra?. In: XXX ENANPAD: Encontro Nacional da Anpad, 2006, Salvador. XXX ENANPAD. Anais Eletrônicos. Salvador: Anpad, 2006.

ALBUQUERQUE, L. G.; BOSQUETTI, M. A. Gestão estratégica de pessoas: Visão do RH X Visão dos Clientes. In: XXIX ENANPAD: Encontro Nacional da Anpad, 2005, Brasília.Anais eletrônicos. Brasília: ANPAD, 2005.

ALBUQUERQUE, L.; FISCHER, A. L. Tendências que orientam as decisões dos formadores de opinião em gestão de pessoas no Brasil - RH 2010. In: XXV ENANPAD: Encontro Nacional da Anpad, 2001, Campinas. Anais eletrônicos. Campinas: ANPAD, 2001.

ALBUQUERQUE, L. G. Estratégias de recursos humanos e competitividade. In: Vieira, M.M., Oliveira, L.M. Administração contemporânea: perspectivas estratégicas. Sao Paulo: Atlas, 1999.

ALMOND, P. et al. Unraveling Home and Host Country Effects: An Investigation of the HR Policies of an American Multinational in Four European Countries. Industrial Relations, Vol. 44, No. 2, April 2005.

ALMOND, P. Re-visiting 'country of origin' effects on HRM in multinational corporations. Human Resource Management Journal, July, 2011, 21 (3), p. $258-271$.

ALVARES K.M. The business of human resources. Human resource management, Spring 1997, Vol. 36, No. 1 p 9.

ANCA-IOANA, M. New Approaches Of The Concepts Of Human Resources, Human Resource Management And Strategic Human Resource Management.
Annals of the University of Oradea, Economic Science Series. Jul2013, Vol. 22 Issue 1, p1520-1525.

ANDERSSON, U.; FORSGREN, M.; HOLM, U. Subsidiary embeddedness and competence development in MNCs - A multi-level analysis. Organization Studies, 2001, 22(6):1013-1034

ANDO, N.; PAIK, Y. Institutional distance, host country and international business experience, and the use of parent country nationals. Human Resource Management Journal, January, 2013, 23 (1), p. 52-71.

ANTHONY, W.P.; PERREWE, P.L.; KACMAR, K. M. Strategic Resource Management. Orlando: Harcourt Brace \& Company, 1996.

ASHTON, C.; HAFFENDEN, M.; LAMBERT, A. The "fit for purpose" HR function. Corporate Research Forum. Strategic HR Review. Vol.4, n.1, Novembro/Dezembro, 2004.

BARDIN, L. Análise de Conteúdo: Lisboa, Edições 70, 1977.

BARTLETT, C. A.; GHOSHAL, S. Tap your subsidiaries for Global Reach. Harvard Business Review, 1986, Vol. 64, No. 6, p. 87 - 94 .

BARTLETT, C. A.; GHOSHAL, S. Gerenciando Empresas no Exterior: A Solução Transnacional. São Paulo: Makron Books, 1992.

BARTLETT, C. A.; GHOSHAL, S. Transnational Management. 2a. ed. Boston: McGraw-Hill,1998.

BEATTY, R.W., SCHNEIER E.C. New HR roles to impact organizational performance: from "partners" to "players". Human Resource Management Journal, Spring 1997, Vol. 36, No. 1 p 29.

BELANGER, J.; EWARDS, P.; WRIGHT, $M$. Best HR practice and the multinational company. Human Resource Management Journal, v. 9, n. 3, p. 145167, 1999. 
BIRKINSHAW, J. M.; MORRISON, A. Configurations of strategy and structure in subsidiaries of multinational corporations. Journal of International Business Studies, v. 26, n. 2, p. 729-754, 1995.

BIRKINSHAW, J.; HOOD, N.; JONSSON, S. Building Firm-Specific Advantages in Multinational Corporations: The Role of Subsidiary Initiative. Strategic Management Journal, v. 19, n.3, p. 221-241, 1998.

BITENCOURT, C. C. A gestão de competências gerenciais - a contribuição da aprendizagem organizacional. Tese (Doutorado em Administração) - Escola de Administração. Porto Alegre: Universidade Federal do Rio Grande do Sul, 2001.

BOZKURT, Ö; MOHR, ALEXANDER T. Forms of cross-border mobility and social capital in multinational enterprises. Human Resource Management Journal, April, 2011, 21 (2), p. 138-155.

BURKE, W.W. What human resource practitioners need to know for the twentyfirst century. Human Resource Management, v. 36, n. 1, p. 29-47, 1977.

CALDAS, M. P.; TONELLI, M. J.; LA, B. M. B. IHRM in developing countries: Does the functionalist vs Critical Debate make sense south of Equator?. BAR. Brazilian Administration Review, v. 8, n. 2, p. 433453, 2011.

CANÇADO, V. L.; COUTINHO, P. T.; ALMEIDA, M. G. R.; SANT'ANNA, A. S. Novos Papéis de Recursos Humanos: Velhas fórmulas em novas embalagens?. In: XXIX ENANPAD: Encontro Nacional da Anpad, 2005, Brasília. XXIX ENANPAD. Anais Eletrônicos. Brasília: ANPAD, 2005.

CARNEIRO, J; ROCHA, A; SILVA, J.F. Challenging the Uppsala internationalization model: a contingent approach to the internationalization of services. $\quad$ BAR - Brazilian Administration Review. April-June, 2008, Vol. 5 Issue 2.
CHILD, J. Theorizing about organization cross-nationally. In: CHENG, J.L.; PETERSON, R.B. (Eds.). Advances in International Management, Vol. 13, JAI Press.

COOPER, D.; SCHINDLER, P. Métodos de pesquisa em administração. 7. ed. Porto Alegre: Bookman, 2003.

D'CRUZ, J. Strategic Management of Subsidiaries. In: ETERMAD, H.; SEGUIN DULUDE, L. (eds). Managing the Multinational Subsidiary, London: Croom Helm, 1986.

DOUTHITT, S; MONDORE, S. Creating a Business-Focused HR Function with Analytics and Integrated Talent Management. People \& Strategy. v. 36, n. 4, p. 16-21, 2013.

DOWLING, P.; WELCH, D. International Human Resource Management. 4. ed. Mason: Thompson, 2005.

EDWARDS, T. et al. Reverse Diffusion in US Multinationals: Barriers from the American Business System. Journal of Management Studies, v. 42, n. 6, p. 124148, 2005.

EDWARDS, T.; KURUVILLA, S. International HRM: national business systems, organizational politics and the international division of labour in MNCs. International Journal of Human Resource Management. v. 16, n. 1, p. 87105, 2005.

EDWARDS, T.; FERNER, A. The Renewed 'American Challenge': A Review of Employment Practice in U.S. Multinationals. Industrial Relations Journal, v. 33, n. 2, p. 94-110, 2002.

FARNDALE, E; SCULLION, H; SPARROW, P. The role of the corporate HR function in global talent management. Journal of World Business, v. 45, n. 2, p. 161-168, 2010.

FENGXIA, Z; SHAOMING, Z. Launching Reverse-Innovated Product From 
Análise da relação entre subsidiária brasileira e matriz de corporação norte-americana com foco na gestão de RH

Emerging Markets To Developed Markets: A Theoretical Framework For Mnc's Decisions. Ama Summer Educators' Conference Proceedings. v. 24, n. 3, p. 283-284, 2013.

FERNER, A.; QUINTANILLA, J. Multinationals and human resource management: between global convergence and national identity. International Journal of Human Resource Management v. 14, n. 3, p. 98-118, 2003.

FERNER, A.; QUINTANILLA, J. Multinationals, national business systems and HRM: the enduring influence of national identity or a process of 'AngloSaxonization'. International Journal of Human Resource Management, v. 9, n. 4, p. 39-57, 1998.

FERNER, A. et al. The Dynamics of Central Control and subsidiary Autonomy in the Management of Human Resources: Case Study Evidence from U.S. MNCs in the UK. Organization Studies 25(3):36391, 2004.

Ferner, A; Belanger, J; Tregaskis, O; Morley, M; Quintanilla, Javier. U.S. multinationals and the control of subsidiary employment policies: Industrial and Labor Relations Review. v. 66, n. 3, p. 645-662, 2013.

FLICK, U. Introdução a pesquisa qualitativa. Porto Alegre, Bookman, 2004.

GAMMELGAARD, J; RITTER, T. Virtual Communities of Practice: A Mechanism for Efficient Knowledge Retrieval in MNCs. International Journal of Knowledge Management, v. 4, n. 2, p. 46-51, 2008.

GODOY, C.; BANDEIRA-DE-MELLO, R.; SILVA, A. Pesquisa qualitativa em estudos organizacionais. São Paulo, Saraiva, 2006.

FOURIE, W. Can MNCs be held morally responsible for the unintended consequences of their operations? African Journal of Business Ethics. V. 7, n. 1, p. 26-46, 2013.
GHOSHAL， S.; NOHRIA， N. Internal differentiation within multinational corporations. Strategic Management Journal, v. 10, n. 4, p. 323-337, 1989.

GUBMAN, E. HR Strategy and planning: From birth to business results. Human Resource Planning. New York: v. 27, n. 1, p. 13-23, 2004.

HANASHIRO, D. M. M.; TEIXEIRA, M. L. M.; ZEBINATO, A. N. Os papéis Desempenhados pelos profissionais de Recursos Humanos Contribuem para a Vantagem competitiva Sustentável?. In: XXV ENANPAD: Encontro Nacional da Anpad, 2001, Campinas. XXV ENANPAD. Anais eletrônicos. Campinas: ANPAD, 2001.

KOPP, R. International Human Resource polices and practices in Japanese, European, and United States multinationals. Human Resource Management. v. 33, n. 4, p. 56-74, 1994.

KOSTOVA, T. Success of the Transnational Transfer of Organizational Practices within Multinational Companies. South Carolina: University of South Carolina, 1998.

JARILLO， J.C.; MARTINEZ， J. L. Different roles for subsidiaries: The case of multinational corporation in Spain. Strategic Management Journal, v. 11, n. 7, p. 501-512, 1990.

LACOMBE, B. M. B.; TONELLI, M. J. O discurso e a prática: o que dizem os especialistas e o que nos mostram as práticas de gestão em RH. Revista de Administração Contemporânea, Curitiba, v. 5, n. 2, p. 157-174, 2001.

LAWLER, J. J.; PO-CHIEN, C; WOONKI, H; SHYH-JER, C; PEICHUAN, W; JOHNGSEOK, B. Going Abroad: Hr Policies, National Ir Systems, And Union Activity In Foreign Subsidiaries Of U.S. Multinationals. Industrial \& Labor Relations Review. v. 66, n. 5, p.1149-1171, 2013. 
LEAVY, B. India: MNC strategies for growth and innovation. Strategy \& Leadership, v. 42, n. 2, p. 30-39, 2014.

MCDONNEL, A; GUNNIGLE, P; LAVELLE, J. Learning transfer in multinational companies: explaining interorganisation variation. Human Resource Management Journal, v. 20, n. 1, p. 2343, 2010.

MCGRAW, P. Influences on HRM practices in MNCs: a qualitative study in the Australian context. International Journal of Manpower, v. 25, n. 6, p. 175197, 2004.

MAZMANIAN, D A.; JUREWTZ，J; NELSON, H. T. The paradox of 'acting globally while thinking locally: discordance in climate change adaption policy. Journal of Environment \& Development, v. 22, n. 2, p. 186-211, 2013.

MILAN, M. Globalization Tendencies In Organizational Architecture In Eu (Societas Europea And Its Impact On Corporate Governance). International Journal of Management Cases. Vol. 13 Issue 4, p. 107-114, 2011.

MIRANDA M.O; MENDES, F.B. The role of subsidiaries from emerging economiesA survey involving the largest Brazilian multinationals.

Thunderbird

International Business Review. Vol. 54 Issue 3, p. 361-371, 2012.

FERNANDES, T.; PROCHNIK, V. Transferência de rotinas em empresas Transnacionais. In: Economia \& Tecnologia, vol. 4 núm. 4, p. 45-62, 2001.

OGBONNAYA, M.U; OGUJIUBA, K; EMMANUEL, C. The Paradox of Globalization and State Fragmentation Since the Twentieth Century. Pakistan Journal of Social Sciences (PJSS), Vol. 32 Issue 2, p. 445-452, 2012.

PARRY, E; DICKMANN, M; MORLEY, M. North American MNCs and their HR policies in liberal and coordinated market economies. International Journal of Human Resource Management, v. 19, n. 11, p. 2024-2040, 2008.

QUINTANILLA, J. Dirección de Recursos Humanos em Empresas Multinacionales: las subsidiarias al descubierto. Madrid: Prentice Hall, 2002.

RAMONA, T; ANCA, S. Human Resource Management - From Function To Strategic Partner. Annals of the University of Oradea, Economic Science Series, Vol. 22 Issue 2, p. 631-638, 2013.

RAMSEY, J R.; BARAKAT, L.; CRETOIU, L.; SHERBAN L. Internationalization and its possible impact on subjective and objective performance: evidence from Brazilian TNCs: Transnational Corporations, Vol. 21 Issue 2, p. 21-26, 2012.

ROCHA, A.; ALMEIDA, V. Estratégias de Entrada e de Operações em Mercados Internacionais. In: TANURE, B.; DUARTE, R. G. (Orgs.). Gestão Internacional. São Paulo: Saraiva, 2006.

RONDINELLI, D.; BLACK, S. Multinational strategic alliances and acquisitions in Central and Eastern Europe: Partnerships in privatization. Academy of Management Executive, v. 14, n. 4, p. 8598, 2000.

ROTH, K; MORRISON, A. J. Implementing global strategy: Characteristics of global subsidiary mandates. Journal of International Business Studies, Vol. 2, n. 2, p. 89-107, 1992.

SAKA, A. Institutional limits to the internationalization of work systems: a comparative study of three Japanese multinational companies in the UK. European Journal of Industrial Relations, vol. 8, n. 3, p. 56-74, 2002.

SCHULER， R.; DOWLING， P.; DE CIERI, H. An integrative framework of strategic international human resource management. International Journal of 
Human Resource Management, v. 4, n. 4, p. 36-56, 1993.

SILVA, N.B; FLEURY, M.T.L. Brazilian Multinational Companies' Subsidiaries Initiative: a typology proposal. Revista Brasileira de Gestão de Negócios, v. 15, n. 46, p. 5-21, 2013.

SLAUGHTER, M J.; D'ANDREA T, L. A. Warning Sign From Global Companies. Harvard Business Review, Vol. 90 Issue 3, p. 74-75, 2012.

SZULANSKI, G. Exploring Internal Stickiness: Impediments to the Transfer of Best Practice within the Firm. Strategic Management Journal, vol. 17, n. 4, p. 2743, 1996.

SUNDARAM, A.K.; BLACK, J.S. The Environment and Internal Organization of Multinational Enterprises. Academy of Management Review, v.17, n.1, p. 729757, 1992.

ULRICH, D._Os Campeões de Recursos Humanos: inovando para obter os melhores resultados. São Paulo: Futura, 1998.

ULRICH, D. Recursos Humanos Estratégicos. São Paulo: Futura, 2000.

VASCONCELOS, F C ; CALDAS, M. P. ; WOOD JR, T . Fusões e Aquisições no Brasil: uma Análise Crítica do Teatro de Operações. Comportamento Organizacional e Gestão, Lisboa, v. 10, p. 43-58, 2004.

YIN, R. K. Estudo de Caso: Planejamento e Método. 3. ed. São Paulo: Bookmam, 1994.

ZESSCHKY, M; WIDENMAYER, B; GASSMANN, O. Organising for reverse innovation in Western MNCs: the role of frugal product innovation capabilities. International Journal of Technology Management, v. 64, n. 2, p. 255-275, 2014. 